\title{
PULSED-LASER INDUCED CHAIN ADDITION REACTION OF BUTANAL TO DIETHYL MALEATE
}

\author{
R. STRINGAT, G. FABRE and M. ALESSANDRI
}

Laboratoire d'Optique Atomique et Moléculaire

\author{
R. FELLOUS \\ Laboratoire de Chimie des Arômes \\ Faculté des Sciences -U.N.S.A. -06108 NICE Cedex 2-FRANCE
}

(Received 1 October, 1993)

By irradiation of a $5 / 1$ mixture of butanal and diethyl maleate with a pulsed Nd-YAG laser $(10 \mathrm{~Hz}$, $13 \mathrm{~ns})$, frequency tripled $(\lambda=355 \mathrm{~nm})$, diethyl butanoyl succinate is formed by addition. The quantum yield is greater than 1 which means that a chain mechanism occurs which was not the case in previous studies with a mercury lamp. The quantum yield is a function of light intensity and can reach 280 in the range explored $\left(\mathrm{I}=3020\right.$ to $\left.\mathrm{I}=0.303 \mathrm{KW} \cdot \mathrm{cm}^{-2}\right)$. The excited aldehyde produces the two radicals $\mathrm{nPr}-\mathrm{CHOH}$ and $\mathrm{nPr}-\mathrm{CO}$. The nucleophilic acyl radical reacts on the diethyl maleate to form an intermediary radical which gives the adduct and a new acyl radical in the presence of an aldehyde molecule. The second radical $\mathrm{nPr}-\mathrm{CHOH}$ captures a hydrogen from the aldehyde producing another acyl radical and butanol.

KEY WORDS: aliphatic aldehydes, $\alpha, \beta$-unsaturated esters, $\gamma$-ketoesters, laser photochemistry, chain addition reaction.

The well known photoaddition of aldehydes to electron deficient double bonds has often been described in works of general interest. ${ }^{1}$ Thus, aliphatic aldehydes can lead, by addition on to $\alpha, \beta$-unsaturated esters, to $\gamma$-ketoesters, via the acyl radical intermediate.

With respect to radical chain photoadditions, a recent survey has been published in "Photochemistry of Organic Synthesis".

Among the most recent studies one can cite that of F. A. Macias et al. ${ }^{3}$ which relates to the photoaddition of the acyl radical to double bonds bearing different electro-withdrawing groups as substituents. The irradiations, performed with filters isolating a spectral band centered at $300 \mathrm{~mm}$, allowed the selective formation of the photoadducts with a chemical yield which decreased when the steric hindrance increased.

With a mercury lamp filtered at $313 \mathrm{~nm}$ (wavelength close to the maximum of absorption of the $n \rightarrow \pi^{*}\left(S_{1}\right)$ transition of the aldehyde), the formation of 
$\gamma$-ketoesters, ${ }^{4}$ which involves the triplet state of the aldehyde, ${ }^{5}$ was obtained with a moderate efficiency and depended upon the ester under consideration. For the addition of butanal to ethyl crotonate or dimethyl fumarate, the quantum yields of formation of the products were 0.05 and 0.10 , respectively. Benzophenone is frequently used as a photosensitizer, to permit improvement in the photochemical efficacy. ${ }^{6}$

In a preceding paper ${ }^{7}$ we showed that, under pulsed laser irradiation $(355 \mathrm{~nm}$, $10 \mathrm{~Hz}, 13 \mathrm{~ns}$ ), pentanal and diethyl maleate (the stereoisomer of diethyl fumarate) could be added without a photosensitizer, with quantum yields as high as 20 . Moreover, these quantitatively significant results were attained with a high selectivity, the photoadduct being almost the only product formed.

We present here the results of a similar study performed by replacing the pentanal by the butanal. It should be noted that $355 \mathrm{~nm}$ is at a wavelength limit (the upper one) for the $n \rightarrow \pi^{*}$ absorption band of the aldehyde.

The exact calculation of the quantum yield (number of molecules of adduct formed/number of photons absorbed) necessitates the precise determination of the light power really absorbed by the mixture alone. Preliminary experiments allowed us to take into account the powers absorbed and reflected by the windows of the irradiation silica cell. Moreover, the light intensity, which appears to be an important parameter, was modified with calibrated filters in order to maintain the interaction area between the beam and the solution at a constant value of $-36 \mathrm{~mm}^{2}$.

For the interval of intensity explored ( 3020 to $\left.0.303 \mathrm{KW} . \mathrm{cm}^{-2}\right)$, it was seen that the absorbance of the solution remains in conformity with Beer-Lambert's law (unsaturated monophotonic absorption) with a very low molar extinction coefficient $\varepsilon=0.009 \mathrm{~mol}^{-1} \cdot \mathrm{cm}^{-1} \cdot l$.

The saturation intensity of the $S_{0} \rightarrow S_{1}$ transition is given by the classical formula $\mathrm{I}_{\mathrm{ss}}=\frac{\mathrm{h} v}{\sigma \tau_{s}}$ where $\sigma$ is the excitation cross section and $\tau_{\mathrm{s}}$ the lifetime of the singlet state. From the relation defining the cross section $\sigma\left(\frac{\mathrm{dN}_{0}}{\mathrm{dt}}=-\sigma \mathrm{N}_{0} \mathrm{I}, \mathrm{N}_{0}\right.$ being the concentration of absorbing species -in number of molecules per unity of volumeand I the light intensity-in number of photons per unit area and second) and from the relation defining the molar extinction coefficient $\varepsilon\left(\frac{\mathrm{dI}}{\mathrm{dz}}=-\frac{\varepsilon}{\log _{10} \mathrm{e}}[\mathrm{c}] \mathrm{I},[\mathrm{c}]\right.$ being the concentration in moles per liter), noting that $\frac{\mathrm{dI}}{\mathrm{dz}}=\frac{\mathrm{dN}_{0}}{\mathrm{dt}}$, the relation $\frac{\varepsilon[\mathrm{c}]}{\log _{10} \mathrm{e}}=\mathrm{N}_{0} \sigma$, i.e. numerically $\sigma\left(\mathrm{cm}^{2}\right)=7.22 .10^{-22} \varepsilon\left(\mathrm{mol}^{-1} . \mathrm{cm}^{-1} . l.\right)$, is obtained. Taking $\tau_{\mathrm{s}}=2.9 \mathrm{~ns},{ }^{8}$ $\mathrm{I}_{\mathrm{ss}}-3.10^{13} \mathrm{~W} \cdot \mathrm{cm}^{-2}$ is obtained; this is effectively much higher than the intensities used in this study. It must be stressed that the preceding $\tau_{\mathrm{s}}$ value characterizes the self-quenching reaction of the excited singlet state with an aldehyde concentration of $0.22 \mathrm{M}$. In the present study, where the concentration was of the order of $10 \mathrm{M}$, this lifetime is highly shortened, which means a still greater value for $I_{s s}$.

Irradiation (in a cylindrical cell with diameter $=12 \mathrm{~mm}$ and length $=25 \mathrm{~mm}$ ) of a butanal/diethyl maleate mixture with a mole ratio of $5 / 1$ resulted in the almost 
exclusive formation of diethyl butanoyl succinate, accompanied by a small amount of butanol.

It must be pointed out that the isolated adduct does not absorb light at $355 \mathrm{~nm}$.

With a sufficient irradiation time, all the maleate can be transformed. If the irradiation is continued after the near-to-total disappearance of the maleate, the compounds formed by irradiation of the pure aldehyde ( $\alpha$-dione, $\alpha$-ketol), ${ }^{9}$ appear logically.

The structure of the products was confirmed using GC/MS. The quantitative determination of the products formed was performed by GC using diglyme as an internal standard.

In contrast to the results obtained with a mercury lamp, where the quantum yield of adduct did not exceed $0.1,{ }^{4}$ quantum yields higher than 1 were obtained; this demonstrates the occurrence of a chain reaction.

The study of the quantum yield $\Phi$ of formation of $\gamma$-ketoester, as a function of the light intensity, showed a remarkable increase when the intensity was decreased (fig. 1) within the limits of the interval explored (from $\Phi=2.77$ to $\Phi=280$ for $\mathrm{I}=$ 3020 to $\mathrm{I}=0.303 \mathrm{KW} \cdot \mathrm{cm}^{-2}$ ).

It must be pointed out that the important differences observed betwen the mercury lamp and the laser irradiation behaviors are not related to concentration conditions.

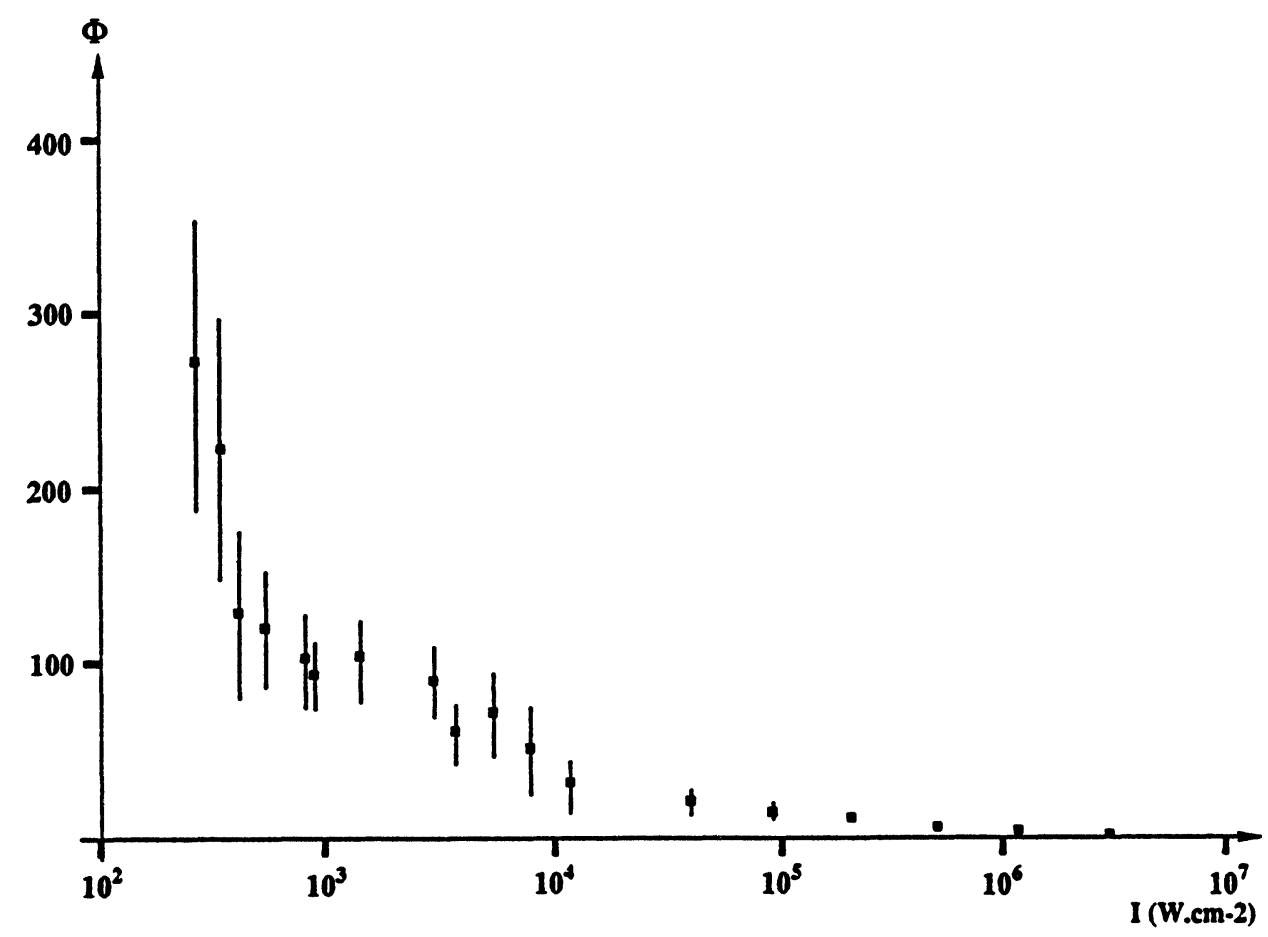

Figure 1 Quantum yield ( $\Phi$ ) for the production of the diethyl butanoyl succinate as a function of light intensity. 
Effectively, the use of a cyclohexane solution at a concentration comparable to those implemented when irradiating with a lamp ${ }^{4}$ (i.e. $0.6 \mathrm{M} \mathrm{n}$-butanal in cyclohexane instead of $9.44 \mathrm{M}$ in the $5 / 1$ mixture), and laser irradiation at $\mathrm{I}=7.8 \times 10^{5} \mathrm{~W} . \mathrm{cm}^{-2}$, led to a quantum yield of $4.3 \pm 1.0$. The result obtained under the present working conditions was $4.9 \pm 1.4$. The similarity of both values proves that the differences in quantum yield are essentially related to the light sources.

By comparing the results of the classical photochemical route 4 (involving the $\mathrm{nPr}-$ $\mathrm{CO}$ and $\mathrm{nPr}-\mathrm{CHOH}$ radicals) with that of the Nd-YAG laser, the principal difference resides in the behavior of the $\mathrm{nPr}-\mathrm{CHOH}$ radical. In our case, the presence of small quantities of butanol in the photochemical products, allows one to consider a specific reaction channel for the nPr-CHOH radical. This radical, by capturing a hydrogen atom coming from another aldehyde molecule, can lead to the formation of butanol and a new acyl radical, therefore, helping in the propagation of the chain (scheme
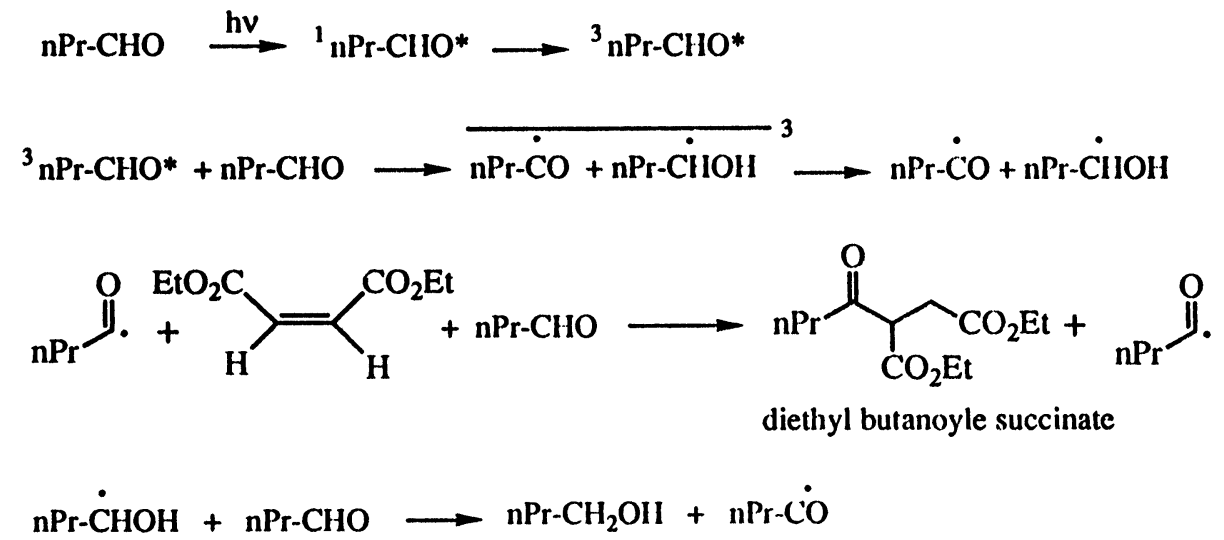

$1)$.

On the other hand, in the experiments performed with the lamp, the R- $\dot{\mathrm{C}} \mathrm{HOH}$ (here $\mathrm{nPr}-\mathrm{CHOH}$ ) radical was seen ${ }^{4}$ to inhibit the formation of the chain (scheme

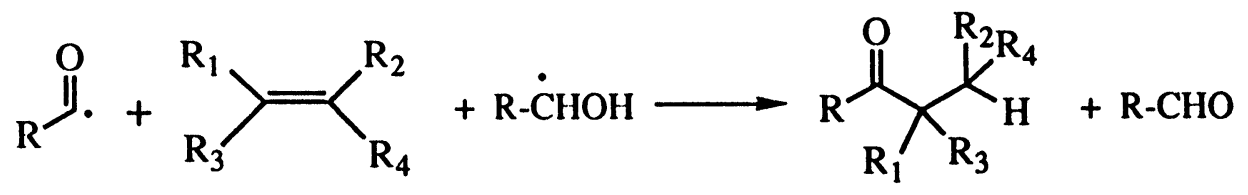

2):

It has been seen that, in the light intensity interval explored, the absorption remains governed by the unsaturated monophotonic absorption $S_{0} \rightarrow S_{1}$ (very low value of the molar extinction coefficient), as with the mercury lamp (low intensity value). However, it is clear that the conditions of preparation of the initial active species ${ }^{1} \mathrm{nPr}-\mathrm{CHO}^{*}$ are considerably different in relation to the molar extinction coefficient and the light intensity values. With the lamp at $313 \mathrm{~nm}^{4}$, the value of $\varepsilon\left(\sim 10 \mathrm{~mol}^{-1}\right.$. $\mathrm{cm}^{-1}$ l.) and the concentration conditions cause a close to total absorption of the 
photons after a path of about $1 \mathrm{~mm}$. By contrast, with the pulsed laser at $355 \mathrm{~nm}$ (very low value of $\varepsilon$ ), the active starting species are produced throughout the cell with a low concentration gradient. Moreover, the values and temporal variations of concentration are very different with the two sources. It is thus not surprising that the reaction dynamics can be very different, especially if various kinetic orders are involved, leading to new quantitatively interesting results. To summarize, the low $\varepsilon$ value at $355 \mathrm{~nm}$ is the main reason for the remarkable results obtained. It involves a high penetration of the laser beam into the medium and, consequently, the large distribution of active species throughout the whole reaction cell.

The reaction kinetics are also helpful in the interpretation of the curve (fig. 1) since active species concentrations depend upon light intensity.

It must be pointed out that $\gamma$-ketoesters are useful synthons which allow (by cyclisation) the preparation of ethylenic or saturated $\gamma$-lactones used in the field of fragrance and flavouring. The method described leads to a clean product with high photochemical efficacy. The curve (fig. 1) allows one to choose the best intensity conditions for the manufacture of the adduct. It is thus possible to predict the possibility of making many tens of $\mathrm{kg}$ per hour, using an excimer laser of average power $35 \mathrm{~W}$, emitting at $351 \mathrm{~nm}(\mathrm{XeF})$, based on the hypothesis that behaviors are approximately the same at 351 and $355 \mathrm{~nm}$.

\section{References}

1. W. M. Horspool, Synthetic organic photochemistry, ed. Plenum Press, (New York, 1984).

D. Elad, in: Organic photochemistry, Vol 2, ed. M. Dekker (New York, 1969) p 168.

2. J. Hutchinson, in: Photochemistry in organic synthesis, ed. J. D. Coyle (The royal society of chemistry, London, 1986), chp 16, p 314.

3. F. A. Macias, J. M. G. Molinillo, I. G. Collado, G. M. Massenet, F. Rodriguez-Luis; Tetrahedron Lett., 31(21), 3063 (1990).

F. A.Macias, J. M.G. Molinillo, G. M. Massenet, F. Rodriguez-Luis; Tetrahedron, 48(16), 3345 (1992).

4. I. Kawenoki, D. Maurel, and J. Kossanyi, Bull. Soc. Chim., France, 11-12, 386 (1980).

5. J. Kossanyi, G. Daccord, S. Sabbah, B. Furth, P. Chaquin, J. C. Andre, and M. Bouchy, Nouv. J. Chimie, 4, 337 (1980).

6. D. R. Hicks, R. C. Anderson and B. Fraser-Reid, Synthetic Comm., 6, 417 (1976).

B. Fraser-Reid, R. C. Anderson. D. R. Hicks, and D. L. Walker, Can. J. Chem., 55, 3986 (1977).

7. R. Stringat, G. Fabre, R. Fellous and P. Paquet, Tetrahedron Lett., 33, 4303 (1992).

8. J. Kossanyi, S. Sabbah, P. Chaquin, and J. C. Ronfart-Haret, Tetrahedron, 37, 3307 (1981).

9. P. Paquet, R. Fellous, R. Stringat, and G. Fabre, Tetrahedron Lett., 33, 485 (1992). 